\title{
Effect of End-of-Life Nursing Education on the Knowledge and Performance of Nurses in the Intensive Care Unit: A Quasi-Experimental Study
}

\section{Sima Sadat Ghaemizade Shushtari}

Ahvaz Jundishapur University of Medical Sciences

Shahram Molavynejad ( $\nabla$ shahrambaraz@ajums.ac.ir)

Ahvaz Jundishapur University of Medical Sciences

Mohammad Adineh

Ahvaz Jundishapur University of Medical Sciences

Mohsen Savaie

Ahvaz Jundishapur University of Medical Sciences

Asaad Sharhani

Ahvaz Jundishapur University of Medical Sciences

\section{Research Article}

Keywords: End-of-life nursing care education, nursing education, knowledge and performance of nurses

Posted Date: November 9th, 2021

DOl: https://doi.org/10.21203/rs.3.rs-993887/v1

License: (9) This work is licensed under a Creative Commons Attribution 4.0 International License. Read Full License 


\section{Abstract}

Background: End-of-life care education is required for nurses to acquire the clinical competence necessary for the improvement of the quality of end-of-life nursing care. The aim of this study was to determine the effect of nursing care education based on End-of-Life Nursing Education Consortium (ELNEC) on the knowledge and performance of nurses working in the intensive care unit (ICU).

Materials and Methods: This quasi-experimental study was conducted with a pretest-posttest design. From among nurses working in the ICU of Golestan and Imam Khomeini hospitals in Ahvaz, Iran, 80 nurses were selected based on the inclusion criteria. They were randomly assigned to the intervention and control groups (40 people in each group) using a table of random numbers. Data were collected using a demographic characteristics form, the ELNEC Knowledge Assessment Test (ELNEC-KAT), and the Program in Palliative Care Education and Practice Questionnaire (German Revised Version; PCEP-GR).

Results: A significant difference was observed between the study groups in terms of the average knowledge score in all 9 modules including nursing care, pain management and control, disease symptom management, ethical/legal issues, culture, communication with the patient and his/her family, loss and grief, death, and quality of life $(\mathrm{QOL})(\mathrm{P}<0.001)$. Moreover, the average performance score of nurses in the fields of preparation for providing palliative care, self-assessment of ability to communicate with dying patients and their relatives, self-assessment of knowledge and skills in palliative care increased significantly in the intervention group compared to the control group $(P<0.001)$.

Conclusions: End-of-life nursing education is recommended as an effective method for promoting knowledge, attitude, performance, and clinical competence among all nurses involved in end-of-life care.

\section{Introduction}

End-of-life care is a complex phenomenon that not only affects the patient, but also nurses and other members of the care team [1]. In this regard, many health care systems in different countries have organized end-of-life care. In addition to the care procedures for patients, end-of-life care also involves care for the patient's family, and affects the patient's quality of life (QOL) [1-3]. Therefore, in order to provide appropriate and effective palliative care services, nurses and other members of the health care team should receive appropriate training in end-of-life care and effective communication with patients and their family members $[2,4]$. One of the most reputable nursing education programs is the End-of-Life Nursing Education Consortium (ELNEC). This program was first designed and implemented by the American Association of Critical Care Nurses (AACN) in 2001[5]. This program is provided in 9 modules to improve the quality of end-of-life care and to improve the vision and attitude of nurses regarding end-oflife care. These 9 modules include principles of end-of-life nursing care, pain management, sign management, ethical/legal issues, cultural considerations, communication, sorrow and mourning, attainment of end-of-life quality care, and preparation and care at the time of death [5-7]. A limited number of studies have been conducted in this field, including the studies by Glover et al.[5] and Sherman 
et al.[8] that have investigated the effectiveness of the ELNEC program in nurses and final year nursing students.

Although the ELNEC program has been developed in the last two decades, many nurses still do not have the necessary knowledge about end-of-life care because it was not included in their educational curriculum [1]. It is recommended that end-of-life care education for nurses involved in this care receive as much attention as other professional care for nurses and be included in nursing education programs [9]. In addition, the results of studies conducted in Iran have shown weaknesses in this field. In the study by Aghaei et al., nurses' knowledge of end-of-life care was low and $55.7 \%$ of nurses stated that they had not received sufficient training in providing this care. However, the participant's attitudes were positive toward patient care in the later stages of life [9]. Hojjati et al. found defects and deficiencies in nurses' knowledge and attitude towards death and their nursing care of dying patients [10]. Despite the widespread holding of this course since 2001 in many countries, no published study or document was found in Iran on the introduction or use of a course on end-of-life nursing care as an internationally recognized course. Therefore, the researchers decided to conduct this study to assess the effect of end-of-life nursing care education based on the ELNEC on the knowledge and performance of nurses working in intensive care units (ICU).

\section{Methods}

\section{Design}

This quasi-experimental study was performed with a pretest-posttest design.

\section{Participants}

This study was conducted in the ICU of Golestan and Imam Khomeini hospitals affiliated to Ahvaz Jundishapur University of Medical Sciences, Iran, from July 2019 to October 2019. Using convenience sampling method, 80 individuals were selected from among nurses who had the study inclusion criteria. Then, they were randomly assigned to intervention and control groups. Due to the limited number of nurses who had the study inclusion criteria and were willing to participate in the study, random sampling was not possible and randomization was done only in the distribution of samples into intervention and control groups. The inclusion criteria included employment at the ICU for at least 1 year, a minimum education of bachelor's degree in nursing, and no history of passing an ELNEC-based training course. The exclusion criteria included reluctance to participate in the study at any time during the study, and participation in and full-time attendance at any briefing or training course.

\section{Data collection tools}


The data collection tools used in this study included a demographic characteristics form, the ELNEC Knowledge Assessment Test (ELNEC-KAT), and the Program in Palliative Care Education and Practice Questionnaire (German Revised Version; PCEP-GR). The demographic information questionnaire including questions on age, sex, and work experience of the participants. ELNEC-KAT consists of 50 fourchoice questions. The scale focuses on 9 issues related to nurses' knowledge of end-of-life care. Each of these 50 questions has a more correct option, which is considered the correct answer $[5,11]$. The PCEPGR examines participant's performance in end-of-life palliative care. This tool is used for the final evaluation of palliative care training courses. This scale consists of 36 items, and its total score varies between 0 and 144. The total score obtained is classified into poor performance ( 0 to 36$)$, average performance (37 to 72 ), acceptable performance (73 to 108), and optimal performance (109 to 144) [12, 13].

\section{Intervention}

Pretest was performed on all participants in the intervention and control groups. The intervention was performed 1 week after the pretest. The designed intervention had two parts. In the first part, nurses in charge of patient care participated in a briefing session on the importance, basics, and application of endof-life care based on the ELNEC. The study method and stages were explained to the nurses. Then, in the next stage, the nurses of the intervention group were divided into 4 groups of 10 individuals and 5 training classes were held for each group, the duration of each session varied between 60 and 90 minutes. In this course, the complete basics of end-of-life palliative care were discussed by the researcher based on the ELNEC. Subsequently, the posttest was performed by the researcher in both groups. The posttest was performed 1 month after the end of the intervention. Finally, in both parts of the tool (knowledge and performance), the score of each subscale in each test was determined and the total score of each participant was calculated in the scale through the aggregation of scores.

\section{Statistical analysis}

In this study, descriptive and analytical statistical analysis methods were used in SPSS software (version 16, SPSS Inc., Chicago, IL, USA). Quantitative variables were reported as mean, standard deviation, and minimum and maximum, and qualitative variables were reported as number (percentage). The normality of quantitative variables was assessed using the Shapiro-Wilk test. Independent t-test, paired sample ttest and Analysis of covariance (ANCOVA) were used to data analysis. The statistical significance level was considered to be 0.05 .

\section{Results}

The mean age and work experience of the participants were $33.00 \pm 4.13$ and $5.26 \pm 2.31$ years, respectively. The number of female nurses was 75 (93.8\%) and the number of male nurses was $5(6.2 \%)$. The number of nurses with bachelor's and master's degrees was $73(91.3 \%)$ and $7(8.7 \%)$, respectively. 
The results of the comparison of nurse's knowledge before and after education (the first specific goal of the study) based on the ELNEC in the intervention and control groups are presented in Table 1. There was a statistically significant difference between the intervention and control group in terms of the mean knowledge in nursing care, pain management and control, symptom management, ethical/legal issues, culture, communication with the patient and his/her family, loss and grief, death, and QOL $(P<0.001)$. The mean total knowledge score of nurses before the intervention $(19.10 \pm 3.91)$, in the intervention group, was significantly lower than the average total knowledge score of nurses after the intervention $(36.69 \pm 6.55)(P<0.001)$. The highest percentage of change in the score of knowledge modules after the intervention was related to the field of death and culture. 
Table 1

Comparison of nurse's knowledge before and after education based on the End-of-Life Nursing Education Consortium

\begin{tabular}{|c|c|c|c|c|c|}
\hline Module & Group & $\begin{array}{l}\text { Before the } \\
\text { intervention }\end{array}$ & $\begin{array}{l}\text { After the } \\
\text { intervention }\end{array}$ & $P^{\star \star}$ & $P^{*}$ \\
\hline \multirow[t]{3}{*}{ Nursing Care } & Control & $2.05 \pm 1.41$ & $2.00 \pm 1.18$ & 0.324 & \multirow[t]{3}{*}{$<0.001$} \\
\hline & Intervention & $2.31 \pm 1.24$ & $4.00 \pm 0.81$ & $\dot{0} 001$ & \\
\hline & $P^{\star \star \star}$ & 0.397 & $<0.001$ & - & \\
\hline \multirow[t]{3}{*}{ Pain management and control } & Control & $1.92 \pm 1.26$ & $2.06 \pm 1.35$ & 0.881 & \multirow{3}{*}{$<.001$} \\
\hline & Intervention & $2.00 \pm 1.12$ & $3.94 \pm 1.01$ & $<0.001$ & \\
\hline & $P^{\star \star \star}$ & 0.777 & $<0.001$ & - & \\
\hline \multirow{3}{*}{$\begin{array}{l}\text { Management of disease } \\
\text { symptoms }\end{array}$} & Control & $2.65 \pm 1.13$ & $2.75 \pm 1.02$ & 0.721 & \multirow[t]{3}{*}{$<0.001$} \\
\hline & Intervention & $2.11 \pm 1.21$ & $3.67 \pm 1.43$ & $<0.001$ & \\
\hline & $P^{\star \star \star}$ & 0.057 & 0.003 & - & \\
\hline \multirow[t]{3}{*}{ Ethical/legal issues } & Control & $2.36 \pm 1.02$ & $2.22 \pm 1.11$ & 0.585 & \multirow[t]{3}{*}{0.001} \\
\hline & Intervention & $1.87 \pm 1.06$ & $3.10 \pm 1.38$ & $<0.001$ & \\
\hline & $P^{\star \star \star}$ & 0.045 & 0.004 & - & \\
\hline \multirow[t]{3}{*}{ Culture } & Control & $2.70 \pm 1.02$ & $2.85 \pm 1.32$ & 0.839 & \multirow[t]{3}{*}{$<0.001$} \\
\hline & Intervention & $2.26 \pm 1.45$ & $4.97 \pm 1.03$ & $<.001$ & \\
\hline & $P^{\star \star \star}$ & 0.133 & $<0.001$ & - & \\
\hline \multirow{3}{*}{$\begin{array}{l}\text { Communication with the patient } \\
\text { and his/her family }\end{array}$} & Control & $2.68 \pm 1.30$ & $2.94 \pm 1.11$ & 0.130 & \multirow[t]{3}{*}{$<0.001$} \\
\hline & Intervention & $2.22 \pm 1.31$ & $4.37 \pm 1.01$ & $<0.001$ & \\
\hline & $P^{\star \star \star}$ & 0.132 & $<0.001$ & - & \\
\hline \multirow[t]{3}{*}{ Grief and loss } & Control & $2.71 \pm 1.10$ & $2.80 \pm 1.28$ & $<0.99$ & \multirow{3}{*}{$<.001$} \\
\hline & Intervention & $2.55 \pm 1.41$ & $5.09 \pm 1.46$ & $<.001$ & \\
\hline & $P^{* \star *}$ & 0.586 & $<0.001$ & - & \\
\hline Death & Control & $2.05 \pm 1.28$ & $2.47 \pm 1.16$ & 0.070 & $\begin{array}{l}< \\
0.001\end{array}$ \\
\hline
\end{tabular}




\begin{tabular}{|c|c|c|c|c|c|}
\hline & \multirow[b]{2}{*}{ Intervention } & & \\
\hline & & $1.37 \pm 0.94$ & $3.94 \pm 0.88$ & $\begin{array}{l}< \\
0.001\end{array}$ & \multirow{5}{*}{$<0.001$} \\
\hline & $P^{\star \star \star}$ & 0.009 & $<0.001$ & - & \\
\hline \multirow[t]{3}{*}{ Patient's quality of life } & Control & $3.08 \pm 1.19$ & $3.17 \pm 1.15$ & 0.484 & \\
\hline & Intervention & $2.30 \pm 1.20$ & $4.26 \pm 0.99$ & $<0.001$ & \\
\hline & $P^{\star \star \star}$ & 0.005 & $<0.001$ & - & \\
\hline \multirow[t]{3}{*}{ Total knowledge } & Control & $22.24 \pm 4.98$ & $24.28 \pm 3.67$ & 0.130 & \multirow[t]{3}{*}{$<0.001$} \\
\hline & Intervention & $19.10 \pm 3.91$ & $36.69 \pm 6.55$ & $<0.001$ & \\
\hline & $P^{\star \star \star}$ & 0.012 & $<0.001$ & - & \\
\hline
\end{tabular}

The results related to the second purpose of this research, which was the comparison of the performance of nurses before and after education based on ELNEC in the intervention and control groups, are presented in Table 2. There was a statistically significant difference between the control and intervention group in terms of the mean of nursing performance subscales of preparation for providing palliative care, self-assessment for the ability to communicate with dying patients and their relatives, and selfassessment of knowledge and skills in palliative care $(P<0.001)$. There was no statistically significant difference between the control and intervention group in terms of the mean performance score of nurses in the attitude towards palliative care $(P=0.943)$. Moreover, the mean performance of all nurses in the intervention group $(72.15 \pm 8.22)$ before the intervention was significantly lower than after the intervention $(100.14 \pm 10.00)(P<0.001)$. The highest percentage of change in the score of performance modules after the intervention was related to preparation for providing palliative care and selfassessment of the ability to communicate with dying patients and their relatives. 
Table 2

Comparison of nurse's performance before and after education based on the End-of-Life Nursing Education Consortium

\begin{tabular}{|c|c|c|c|c|c|}
\hline Module & Group & $\begin{array}{l}\text { Before the } \\
\text { intervention }\end{array}$ & $\begin{array}{l}\text { After the } \\
\text { intervention }\end{array}$ & $P^{* *}$ & $P^{*}$ \\
\hline \multirow[t]{3}{*}{$\begin{array}{l}\text { Preparations for providing } \\
\text { palliative care }\end{array}$} & Control & $26.25 \pm 6.29$ & $\begin{array}{l}26.13 \pm \\
5.57\end{array}$ & 0.557 & \multirow[t]{3}{*}{$<0.001$} \\
\hline & Intervention & $23.77 \pm 5.15$ & $\begin{array}{l}38.43 \pm \\
4.47\end{array}$ & $<0.001$ & \\
\hline & $P^{* \star *}$ & 0.056 & $<0.001$ & - & \\
\hline \multirow[t]{3}{*}{ Attitudes toward palliative care } & Control & $23.65 \pm 3.71$ & $\begin{array}{l}24.02 \pm \\
3.56\end{array}$ & 0.803 & \multirow[t]{3}{*}{0.943} \\
\hline & Intervention & $23.84 \pm 2.76$ & $\begin{array}{l}23.80 \pm \\
4.43\end{array}$ & 0.806 & \\
\hline & $P^{\star \star \star}$ & 0.648 & 0.965 & - & \\
\hline \multirow[t]{3}{*}{$\begin{array}{l}\text { Self-assessment of ability to } \\
\text { communicate with patients }\end{array}$} & Control & $14.82 \pm 4.57$ & $\begin{array}{l}15.05 \pm \\
3.59\end{array}$ & 0.657 & \multirow[t]{3}{*}{$<0.001$} \\
\hline & Intervention & $14.32 \pm 3.42$ & $\begin{array}{l}23.28 \pm \\
2.64\end{array}$ & $<0.001$ & \\
\hline & $P^{\star \star \star}$ & 0.581 & $<0.001$ & - & \\
\hline \multirow[t]{3}{*}{$\begin{array}{l}\text { Self-assessment of knowledge } \\
\text { and skills in palliative care }\end{array}$} & Control & $12.00 \pm 3.26$ & $\begin{array}{l}11.54 \pm \\
3.18\end{array}$ & 0.113 & \multirow[t]{3}{*}{$<.001$} \\
\hline & Intervention & $10.77 \pm 2.77$ & $\begin{array}{l}14.63 \pm \\
2.35\end{array}$ & $<0.001$ & \\
\hline & $P^{* \star *}$ & 0.074 & $<0.001$ & - & \\
\hline \multirow[t]{3}{*}{ Total performance of nurses } & Control & $\begin{array}{l}76.77 \pm \\
12.78\end{array}$ & $\begin{array}{l}76.75 \pm \\
10.44\end{array}$ & 0.478 & \multirow[t]{3}{*}{$<0.001$} \\
\hline & Intervention & $72.15 \pm 8.22$ & $\begin{array}{l}100.14 \pm \\
10.00\end{array}$ & $<.001$ & \\
\hline & $P^{\star \star \star}$ & 0.062 & $<0.001$ & - & \\
\hline
\end{tabular}

\section{Discussion}

The results of this study show a significant increase in the mean of nurse's knowledge scores in all 9 fields of end-of-life care knowledge after the intervention. These results are consistent with the findings of 
Glover et al [5]. However, the present study and above study differed in the samples studied; the study by Glover et al, was conducted on final year nursing students, while the present study was performed on nurses working in the ICU. This can be the cause of differences between the results of these two studies. One of the most important differences is the greater clinical experience of nurses working in the ICU compared to students. Undoubtedly, employed nurses have had more exposure to patients at the end of their lives and have had more experience in providing care to patients and their families. This can be effective in improving the quality of knowledge and performance. The findings of the present study indicate that participation in ELNEC training courses has increased nurses' knowledge in all fields, especially in death and culture. However, in the study by Glover et al., the highest percentage of changes was related to palliative care, management of symptoms, communication, and elimination of grief-related loss [5]. Numerous items in the questionnaire showed that nurses had a relatively high level of prior knowledge in various fields of end-of-life care such as pain assessment and management, as well as the basic principles of nursing such as healing, suffering, and QOL of patients and their families. This may be due to the nurses' knowledge of the general principles of nursing that they have learned during their academic studies, or due to the similarity of the educational content to the principles they have performed in sedative care at the end of life in the ICU.

In relation to the role of experience, other researchers have found that experienced nurses scored higher than less experienced nurses, meaning that nursing training and experience led to overall knowledge about palliative care [4]. These findings suggest that nurses can use the content of palliative care and end-of-life care education in the standard nursing curriculum using the ELNEC course, and any overlap in the content will have positive learning outcomes for them. Furthermore, nursing students may need to reinforce materials related to communication skills and grief in their courses $[14,15]$. Previous researches have shown the nurse's desire to become more prepared to care for dying people [16, 17]. In this regard, the need for separate courses on these topics will decrease if the content of palliative care is included in student's curricula. The results of the present study are consistent with the results of the study conducted by Conner et al. They provided an online course on death and dying people and reported a significant improvement in nurse's attitudes toward caring for dying people [18]. The results of the present study showed that nurses can use their knowledge of end-of-life care, which is a multimedia approach to promoting end-of-life care. This finding is consistent with the findings Jackson and Motley [19].

The second objective of the present study was to investigate the effect of education on nurse's performance in relation to end-of-life care. Among the 4 aspects studied, the training course was found to improve the performance of ICU nurses in the 3 aspects of preparation for palliative care, self-assessment of the ability to communicate with dying patients and their relatives, and self-assessment of knowledge and skills in palliative care. Only in the field of attitudes towards palliative care, no significant improvement was observed in the nurse's performance. This can be due to the established and stable attitudes of clinical nurses regarding their beliefs about palliative care. It seems that longer and deeper educational processes are required to induce more change in the attitudes of nurses. However, in areas in which communication and skill were desired, the ELNEC-based training course had a significant effect on improving nurse's performance. This significant effect may indicate that short-term training courses have 
a more favorable effect on skills than attitudes. The results of the present study are consistent with the findings of the study by Tamaki et al [20].

In this study, a training course was presented to improve the performance of nurses in the field of end-oflife care, and in the intervention group, improvement was observed in skills in physical performance assessment, psychological care, and confidence in providing end-of-life care. These results show that end-of-life care training enables nurses to enrich their skills in realistic situations [20]. In confirmation of the findings of the present study, Luctkar-Flude et al, reported that training courses lead to valid emotional responses to realistic patient care scenarios and lead to their imitation in real clinical conditions [21]. Heidari et al, found that posttest time is an important factor in the evaluation of training courses [22]. In this study, the researcher decided that the posttest should be implemented 1 month after the end of the training course to control the effect of the short duration of education. This is one of the important differences between the present study and some other studies in this field, including the studies by Glover et al.[5] and Tamaki et al.[20] Further studies are required to compare several different educational strategies (both in the classroom and hospital) for end-of-life palliative care in order to identify their strengths and weaknesses. This will enable nursing educators to use the best educational approach or a combination of several strategies for nurses. In addition, it is recommended that future researches evaluate and develop interactive learning activities that improve nurse's ability in difficult clinical projects.

\section{Conclusion}

The ELNEC-based training course is an effective method to increase nurse's knowledge and performance in relation to palliative and end-of-life care. Due to the growing population of the elderly in Iran, as well as around the world, courses such as ELNEC help nurses to provide the necessary and adequate supportive care to patients and their companions.

\section{Abbreviations}

ELNEC: End-of-Life Nursing Education Consortium

ICU: intensive care unit

ELNEC-KAT: End-of-Life Nursing Education Consortium Knowledge Assessment Test

PCEP-GR: Program in Palliative Care Education and Practice Questionnaire -German Revised Version

QOL: quality of life

AACN: American Association of Critical Care Nurses

\section{Declarations}

\section{Ethics approval and consent to participate}


This study was approved by the Ethics Committee of Ahvaz Jundishapur University of Medical Sciences (decree code: IR.AJUMS.REC.1398.129). Ethical considerations were in accordance with the Helsinki Declaration 1995, revised 2001. The aim and method of the study were explained to the nurses and their questions were answered by the first researcher. They could withdraw from the study at any time without any effect on their caring process. The written informed consent form was signed by those nurses who willingly agreed to take part in this study. Their confidentiality and anonymity were ensured throughout the study process.

\section{Consent for publication}

Not applicable.

\section{Availability of data and material}

Data may be available by request submitted to the corresponding author.

\section{Competing interests}

All authors report no conflicts of interest. The authors alone are responsible for the content and writing of this article.

\section{Funding}

There was no funding.

\section{Authors' contributions}

Study concept and design: G. SS., M. S., A.M., and S.M; analysis and interpretation of data: S.A.; drafting of the manuscript: G. SS., M. S., A.M., S.M. and S.A; critical revision of the manuscript for important intellectual content: G. SS., M. S., A.M., S.M. and S.A.

All authors have read and approved the manuscript

\section{Acknowledgements}

We would like to thank the officials and staff of Golestan and Imam Khomeini hospitals in Ahvaz, the participants, and all those who helped us to conduct this research.

\section{References}

1. O'Shea ER, Mager D. End-of-life nursing education: Enhancing nurse knowledge and attitudes. Applied Nursing Research. 2019;50:151197.

2. Ferrell $B$, Malloy P, Virani R. The end of life nursing education nursing consortium project. Annals of Palliative Medicine. 2015;4(2):61-9. 
3. Skar A, Juvet L, Smedslund G, Bahus MK, Pedersen R, Fure B. NIPH Systematic Reviews: Executive Summaries. End-of-Life Care - How to Find the Appropriate Level and Intensity of Medical Treatment of Seriously III and Dying Patients. Oslo, Norway: Knowledge Centre for the Health Services at The Norwegian Institute of Public Health (NIPH) Copyright (c)2014 by The Norwegian Institute of Public Health (NIPH). 2014.

4. Cleary AS. Teaching end-of-life care to baccalaureate nursing students: lessons learned. International journal of palliative nursing. 2017;23(12):606-10.

5. Glover TL, Garvan C, Nealis RM, Citty SW, Derrico DJ. Improving End-of-Life Care Knowledge Among Senior Baccalaureate Nursing Students. The American journal of hospice \& palliative care. 2017;34(10):938-45.

6. Kopka JA, Aschenbrenner AP, Reynolds MB. Helping Students Process a Simulated Death Experience: Integration of an NLN ACE.S Evolving Case Study and the ELNEC Curriculum. Nursing education perspectives. 2016;37(3):180-2.

7. Mazanec P, Ferrell B, Malloy P, Davis A, Lippe M, Shillam C. An Innovative, Interactive Online ELNECUndergraduate Curriculum for Nursing Students (FR482E). Journal of pain and symptom management. 2018;55(2):636.

8. Sherman DW, Matzo ML, Pitorak E, Ferrell BR, Malloy P. Preparation and care at the time of death: content of the ELNEC curriculum and teaching strategies. Journal for nurses in staff development: JNSD : official journal of the National Nursing Staff Development Organization. 2015.

9. Aghaei M, Mohajjel Aghdam A, Bodaghi S, Azami Agdash S. Knowledge and Attitude of Nurses Toward Caring for End of Life Patients. Iran Journal of Nursing. 2017;30(107):74-82.

10. Hojjati H, Hekmati Pour N, Nasrabadi T, Hoseini Attitudes of Nurses towards Death. Journal of Health and Care. 2015;17(2):146-53.

11. Lange JW, Shea J, Grossman SC, Wallace M, Ferrell BR. Validation of the End-of-Life Nursing Education Consortium Knowledge Assessment Test: An Abbreviated Version. Journal of Hospice \& Palliative Nursing. 2009;11(5):284-90.

12. Fetz K, Wenzel-Meyburg U, Schulz-Quach C. Validation of the German revised version of the program in palliative care education and practice questionnaire (PCEP-GR). BMC palliative care. 2017.

13. Sullivan AM, Lakoma MD, Billings JA, Peters AS, Block SD. Teaching and learning end-of-life care: evaluation of a faculty development program in palliative care. Acad Med. 2005;80(7):657-68.

14. Kearns T, Cornally N, Molloy W. Patient reported outcome measures of quality of end-of-life care: A systematic review. Maturitas. 2017;96:16-25.

15. Smith MB, Macieira TGR, Bumbach MD, Garbutt SJ, Citty SW, Stephen A, et al. The Use of Simulation to Teach Nursing Students and Clinicians Palliative Care and End-of-Life Communication: A Systematic Review. The American journal of hospice \& palliative care. 2018;35(8):1140-54.

16. Carmack JN, Kemery S. Teaching Methodologies for End-of-Life Care in Undergraduate Nursing Students. The Journal of nursing education. 2018;57(2):96-100. 
17. Gillan PC, van der Riet P, Jeong S. Australian nursing students' stories of end-of-life care simulation. Nursing \& health sciences. 2016;18(1):64-9.

18. Conner N, Loerzel V, Uddin N. Nursing Student End-of-Life Care Attitudes After an Online Death and Dying Course. Journal of Hospice \& Palliative Nursing. 2014;16:374-82.

19. Jackson M, Motley C. End-of-Life Educational Seminar in a Prelicensure Bachelor of Science in Nursing Program. Journal of Hospice \& Palliative Nursing. 2014

20. Tamaki T, Inumaru A, Yokoi Y, Fujii M, Tomita M, Inoue Y. The effectiveness of end-of-life care simulation in undergraduate nursing education: A randomized controlled trial. Nurse education today. 2019;76:1-7.

21. Luctkar-Flude $M$, Wilson-Keates $B$, Larocque M. Evaluating high-fidelity human simulators and standardized patients in an undergraduate nursing health assessment course. Nurse education today. 2012;32(4):448-52.

22. Heidari M, Hoseinkhani N, Norouzzadeh R. Education for nurses about End-of-Life Concerns of the Elderly. 2 Journal of Nursing Education. 2018;7(2):35-44 